\title{
Aortic grafts: Is math the right angle?
}

\author{
Jennifer Chung, MD, MSc, and Maral Ouzounian, MD, PhD
}

\footnotetext{
From the Division of Cardiac Surgery, Department of Surgery, Peter Munk Cardiac Centre, University of Toronto, Toronto, Ontario, Canada.

Disclosures: Authors have nothing to disclose with regard to commercial support.

Received for publication March 19, 2017; accepted for publication March 21, 2017; available ahead of print April $27,2017$.

Address for reprints: Maral Ouzounian, MD, PhD, Peter Munk Cardiac Centre, 200 Elizabeth St, 4N-464, Toronto, Ontario M5G 2C4, Canada (E-mail: Maral.ouzounian@uhn.ca).

J Thorac Cardiovasc Surg 2017; 154:418

$0022-5223 / \$ 36.00$

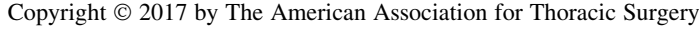

http://dx.doi.org/10.1016/j.jtcvs.2017.03.094
}

In this issue of the Journal, Campo and colleagues ${ }^{1}$ describe a methodical approach to a common question encountered in aortic surgery: how should one best shape the graft used to replace the aorta? The ascending aorta has a 3-dimensional curve, whereas commercially available grafts are straight tubes. The pleated design of grafts allows for some room for error, but misjudgment in length and beveling may result in concerning kinks. Most aortic surgeons have developed their own approaches to this problem, including measuring grafts when they are pressurized, suturing the lesser curve if the resultant graft is too long, or simply gaining the experience to judge the ideal length and shape of the graft, tailored to each individual patient. Campo and colleagues ${ }^{1}$ propose their own solution to this problem: by using simple geometry, they provided us with an equation for the length to which one side of a graft is shortened, to introduce a $90^{\circ}$ curve. A table is also provided that is based on the chosen length and diameter of the graft. Curvature along a circle, rather than a parabola or any other valid curve, is assumed.

Naturally, surgeons do not always want a $90^{\circ}$ curve, the extent of the aorta that is to be replaced varies, and various diameters may be chosen with variable lengths of graft. The equation offered by Campo and colleagues ${ }^{1}$ is thus of limited versatility. By using simple geometry again, however, we can easily generalize their findings. The amount by which to shorten the graft is in fact independent of the length of the graft. It depends only on the amount of desired curvature and the diameter of the chosen graft. It is simply as follows (where $\Delta l$ is change in length, $\theta$ is the angle of desired curvature in degrees, and $d$ is the diameter of the graft):

$$
\Delta l=\frac{\pi \theta d}{180} \approx 0.02 \times \theta \times d
$$

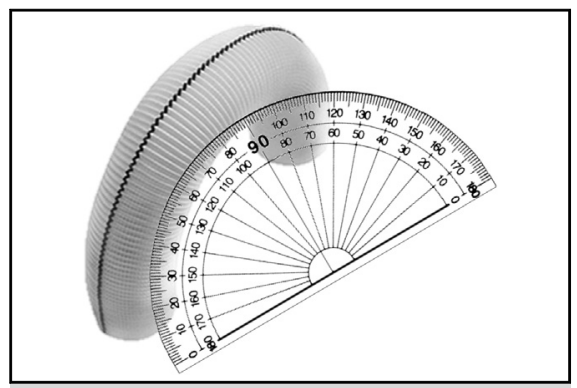

How much precision is needed when shaping an aortic graft?

\section{Central Message}

Creating a preshaped curve in polyester grafts is one of many ways to avoid graft kinking during aortic repair.

See Article page 414

It is an interesting proposal by Campo and colleagues ${ }^{1}$ to develop a rigorous approach to this aspect of aortic surgery, and the 3-dimensional reconstruction they include shows a well-shaped graft. Even in their accompanying visual materials, however, one can appreciate that their shortening stiches occur at an angle and over a greater length of graft than that by which to shorten the graft. At what angle is best? Over what length of graft should the shortening occur? Would the result be more pleasing if the shortening were to occur gradually over the circumference of the graft, rather than cinching the graft down at one individual point? How do such factors as graft beveling, a noncircular distal anastomosis, and the depth and spacing of suture bites alter their solution? The proposed formula seems at once unnecessarily complicated and not complex enough to solve the problem at hand. At the end of it all, we wonder whether graft shaping is simply part of the art, rather than the science, of cardiac surgery.

\section{Reference}

1. Campo JJ, Yamashita MH, Malaisrie SC. Creating a $90^{\circ}$ curve in polyester grafts during thoracic aortic surgery using the pleat technique. J Thorac Cardiovasc Surg. 2017; 154:414-6. 